\title{
High-Temperature Properties of Ceramic Fibers and Insulations for Thermal Protection of Atmospheric Entry and Hypersonic Cruise Vehicles
}

Demetrius A. Kourtides, Ames Research Center, Moffett Field, California

William C. Pitts, Eloret Institute, Palo Alto, California

Myrian Araujo, San Jose State University, San Jose, California

R. S. Zimmerman, University of Wyoming, Laramie, Wyoming

February 1988

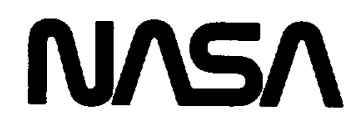

National Aeronautics and

Space Administration

Ames Research Center

Moffett Field, California 94035 

HIGH-TEMPERATURE PROPERTIES OF CERAMIC FIBERS AND INSULATIONS FOR THERMAL PROTECTION OF ATMOSPHERIC ENTRY AND HYPERSONIC CRUISE VEHICLES

\author{
Demetrius A. Kourtides \\ NASA Ames Research Center, Moffett Field, CA 94035 \\ William C. Pitts \\ Eloret Institute, Palo Alto, CA \\ Myrian Araujo \\ San Jose State University, San Jose, CA \\ and
}

R. S. Zimmerman

University of Wyoming, Laramie, WY

NOMENCLATURE

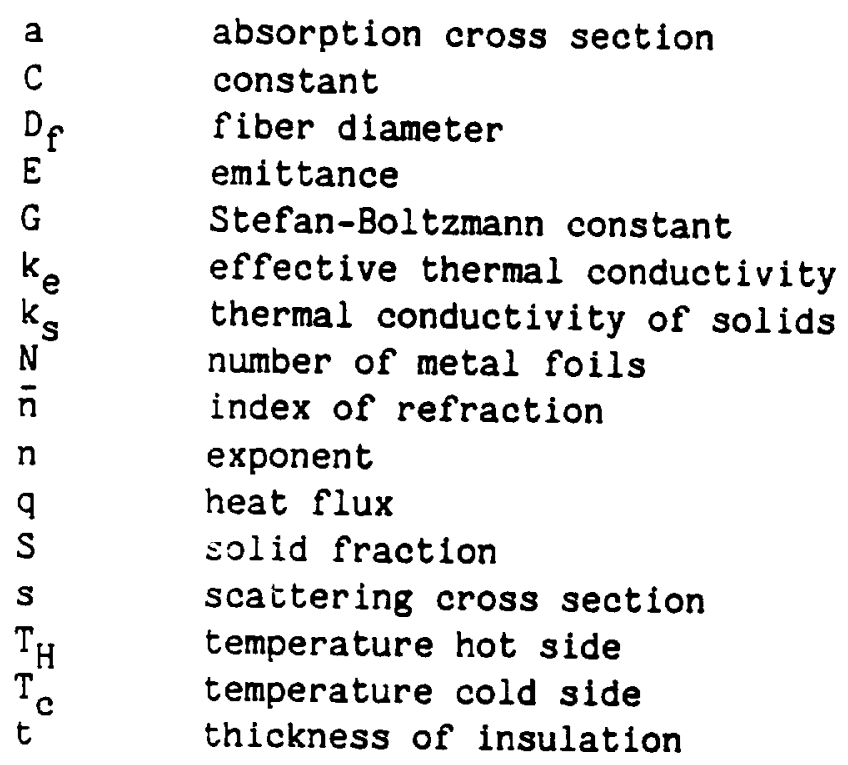

\title{
ABSTRACT
}

Multilayer insulations which will operate in the $500^{\circ} \mathrm{C}$ to $1000^{\circ} \mathrm{C}$ temperature range are being considered for possible applications on aerospace vehicles subject to convective and radiative heating during atmospheric entry. The insulations described in this paper consist of ceramic fabrics, insulations, and metal foils quilted together using ceramic thread. As these types of insulations have highly anisotropic properties, the total heat transfer characteristics of these insulations must be determined. Data are presented on the thermal diffusivity and thermal conductivity of four types of multilayer insulations and are compared to the baseline Advanced Flexible Reusable Surface Insulation (AFRSI) currently used on the Space Shuttle Orbiter. In addition, the high-temperature properties of the fibers used in these multilayer insulations are discussed. The fibers investigated included 
silica and three types of aluminoborosilicate (ABS). Static tension tests were performed at temperatures up to $1200^{\circ} \mathrm{C}$ and the ultimate strain, tensile strength, and tensile modulus of single fibers were determined.

\section{INTRODUCTION}

A prime consideration in the thermal protection of aerospace vehicles is the requirement for highly efficient lightweight thermal insulations. Even though existing flexible insulations, such as the Space Shuttle Orbiter's Advanced Flexible Reusable Insulations (AFRSI) provide excellent thermal protection for large portions of the Orbiter as reported previously (refs. 1-3), there is a need to develop more efficient high temperature flexible insulations for other future space vehicles such as the Space Shuttle II, the Aeroassisted Orbital Transfer Vehicle and the Aeroassist Flight Experiment (AFE; ref. 4).

A significant advance in thermal insulation for cryogenic applications was the development of multilayer insulation technology described previously (refs. 5 and 6 ). Cryogenic insulation technology is an important consideration for hypervelocity cruise vehicles which involve long-term propellant storage requirements. However, this type of insulation has been studied at lower temperatures, and relatively little data and little practical experience have been reported for insulations in the temperature range of $900^{\circ} \mathrm{C}$ to $1100^{\circ} \mathrm{C}$.

A potential application for such a multilayer insulation would be as a thermal protection system for the aerobrake of the AFE. Depending on the exact location of the insulation, whether in the base region of the aerobrake or the front, the maximum heating rate that the insulation may experience could reach $0.5 \mathrm{~W} / \mathrm{cm}^{2}$ in the base region or $30 \mathrm{~W} / \mathrm{cm}^{2}$ in the front of the aerobrake (ref. 7). Figure 1 shows the stagnation point heating rate and dynamic pressure during an atmospheric pass of the aerobrake. As shown, the maximum heating rate is reached at approximately $100 \mathrm{sec}$. This is true also for the base region. The multilayer insulations exposed to lower heating rates would reach maximum back-face temperature at approximately $400 \mathrm{sec}$ at which time the pressure is essentially that of space. Because of this, appropriately designed multilayer insulation could operate especially efficiently within the heating and pressure environment of the AFE.

The purpose of this study was to validate the concept of using quilted ceramic fiber multifoll insulations for these types of applications and to investigate the thermal efficiency at high temperatures and partial vacuum conditions of these insulations in order to establish some baseline data upon which improvements can be made in terms of thermal performance and density. For example, in this study, the insulations were made up of multiple stainless steel foil radiation shields, $0.005 \mathrm{~cm}$ thick, separated by an aluminoborosilicate (ABS) scrim cloth. In actual application, a thinner foil could be used to reduce the density while maintaining the radiative properties of the system. The ceramic scrim cloth was used to maintain an effective separation between the foils without adding a significant conductive path to the system. Various types of fibrous ceramic insulations were utilized on top of the 
multifoil configuration and the whole assembly was quilted in a lightweight ABS fabric and sewn with ABS thread. This approach of combining a flexible ceramic insulation with a multifoil assembly has not been evaluated previously.

The intent of this study was to provide some data on the heat transfer properties of insulations suitable for elevated temperature, vacuum environment. A secondary objective was to provide a one-dimensional heat transfer analytical prediction of the overall thermal performance of the multilayer insulation system. A brief analysis of the one-dimensional heat transfer in multilayer systems is presented together with data on the properties and thermal performance of four multilayer insulations.

An important design consideration in the construction of these insulations is the tenacity or strength of the ceramic fibers used in the fabrics, sewing thread, and scrim cloth of these insulations, especially at high temperatures. The overall strength of the quilted insulation is important since the insulations may be exposed to severe aerodynamic loads. The mechanical properties of the ABS fibers used in the fabric of the multilayer insulations are compared with silica fibers used in the fabrication of the AFRSI.

\section{DISCUSSION AND. RESULTS}

A major consideration in the development of elevated temperature multilayer insulation is the evaluation of the heat transfer parameters which govern the performance of this type of system. These are the thermophysical properties of the components and the physical arrangement of the components to form the insulation system. Heat transfer in multilayer insulations is, in the general case, by conduction, convection, and radiation. For space or vacuum applications, the convection mechanism may be neglected as the gas phase is at a greatly reduced pressure. The heat transport processes which are to be considered are conduction through the solid phase of the insulation and radiation. The radiation becomes the dominant mechanism as temperature increases, whereas conduction determines the lower limit of thermal conductivity at lower temperatures. The heat transfer problem in insulations is very complex. For multilayer insulation having a very small separation such as scrim cloth between the folls, an approximation of the total heat transfer in the whole configuration may be estimated by treating the individual components independently. The total heat transfer through this type of insulation may be expressed as follows:

$$
q(\text { total })=q(\text { radiation })+q(\text { gas conduction })+q(\text { solid conduction })
$$

Since the gas conduction is minimal for space applications, the main mechanisms for heat transfer are radiation and solid conduction. An analytical model has been developed previously (ref. 8) which provides an approximate solution to the heat transfer problem and considers both the radiation and solid conduction in multilayer insulations. The solution used combines the separate mechanisms in multilayer insulations in the following manner: 


$$
k_{e}=c(1-S) k_{s} D_{f}^{n}+\frac{\bar{n}^{2} G\left(T_{H}^{2}+T_{c}^{2}\right)\left(T_{H}+T_{c}\right) t}{(a-2 s)(t / 2)+(N-1)[(2 / E)-1]}
$$

Even though equation (2) does not provide an exact description of the heat transfer characteristics, it shows the importance of some of the properties of the components and geometry in multilayer insulations. For example, to achieve a lower thermal conductivity in the entire system $\left(k_{e}\right)$, a larger number of foils (N) having low emittance (E) at elevated temperatures is desired. Equation (2) also shows the improtance of other parameters such as the fiber diameter $\left(D_{f}\right)$ in the insulation and the thermal conductivity of the individual components $\left(k_{s}\right)$.

In the present study, a $0.005-c m-t h i c k$ stainless steel foil was used as the radiation shield material because of its relatively low emittance and high reflectance at higher temperatures. It was separated with an ABS scrim cloth. The insulations used had a fiber diameter of 2-5 $\mu \mathrm{m}$ depending on which fibrous felt was used. In this study the insulation with the larger diameter fibers had the highest back-face temperatures as will be shown later in the paper. In general, equation (2) shows the influence of the optical properties of both the insulation and foil materials, the number of foils, and the physical and thermal properties of the components (such as density and thickness of insulation), fiber diameter, and the boundary temperatures on the heat transfer properties of the multilayer assembly.

Using these parameters as a guide, four experimental multilayer insulations were fabricated and their heat transfer characteristics were determined.

\section{DESCRIPTION OF MATERIALS}

\section{Multilayer Insulations}

The general material considerations for the insulations are retention of mechanical properties over the specified temperature range, density, availability of materials, and ease of fabrication. Specific conductive heat transfer parameters are thermal conductivity, geometry, thickness, and fiber diameter. Heat conduction through the fibrous insulations has been demonstrated previously (ref. 8) to be a function of the thermal conductivity and mechanical properties of the fibers, the pressure on each fiber contact, the number of fibers, packing geometry, and the temperature difference per unit thickness. In the case of multilayer insulations, local variations in compression and the thermal resistance at each contact point, especially between the foils, have a great effect on the heat transfer properties of the multilayer insulation assembly.

In the present study, the foils were separated with an ABS scrim cloth, but this separation was not completely effective because of the stitching process used in fabrication of the insulations. The spacer or scrim cloth used had an open weave configuration in order to take advantage of the radiative properties such as reflectance of the stainless steel foil which acts as 
the radiation shield in the multilayer assembly. The materials selected for study, their application and reasons for selection are summarized in table 1.

The insulations were sewn with an ABS thread at $2.54 \mathrm{~cm}$ centers similar to the assembly and stitching process which has been used previously for the AFRSI (ref. 3). The typical configuration of the multilayer insulation is shown in figure 2. The insulations were fabricated with a top and bottom ABS fabric. All configurations contained alternating layers of stainless steel foil and an ABS scrim cloth towards the bottom of the insulation. To assess the effectiveness of various insulations, four commercially available fibrous ceramic insulations were used in the construction of the multilayer configurations. A description of the materials used in the fabrication of the multilayer insulations is shown in table 2. The densities of the insulations in the final configurations were slightly higher than the as received condition because of the compaction of the insulation in the fabricated multilayer insulations and the thickness of the foils. In real applications, much thinner foils could be used. The different compaction characteristics of the insulations also resulted in small differences in the thickness of the insulations.

Some of the properties of the insulations used are shown in table 3 . Prior to fabricating the configurations, all of the components, with the exception of the thread, were heat-cleaned to remove any organic sizing material. The configurations were also heat cleaned at $500^{\circ} \mathrm{C}$ for $3 \mathrm{hr}$ to remove the sizing from the ABS thread.

The reflective shield used in these insulations was a stainless steel foil without any special finish. Infrared reflectance measurements were performed on the foils using a Bio-Rad Model FTS-40 spectrophotometer over the wave region of 2.5 to $20 \mathrm{um}$. The spectral reflectance of the foil before and after heating in air at $800^{\circ} \mathrm{C}$ for $30 \mathrm{~min}$ is shown in figure 3 . As it can be seen, there is a reduction in the reflectance of the heated foil in the 2.5 to 7 um wavelength range, but the reflectance is approximately the same at the higher wavelengths. The high reflectance points to the effectiveness of this foil as a radiation shield from about $5 \mu \mathrm{m}$ and longer wavelengths. For an optimized system higher reflectance at shorter wavelengths is desirable.

\section{Fibers}

Strength of the fabrics used in the fabrication of these insulations is also a consideration, especially if these insulations are to be exposed to aerodynamic loads at high temperatures (ref. 9). The ABS fiber used in the yarns of the fabric has a composition of $62 \% \mathrm{Al}_{2} \mathrm{O}_{3}, 24 \% \mathrm{SiO}_{2}, 14 \% \mathrm{~B}_{2} \mathrm{O}_{3}$. It is designated as $A B S\left(14 \% \mathrm{~B}_{2} \mathrm{O}_{3}\right)$ in this paper.

The mechanical properties of this fiber were measured along with the two other types of ABS fibers and the silica fiber used in the AFRSI. The second ABS fiber has the same composition as the first fiber except that it is $70 \%$ crystalline compared to the first fiber which is amorphous (ref. 10). It is designated in this paper as ABS (14\% $\mathrm{B}_{2} \mathrm{O}_{3}, 70 \%$ Crystalline). The composition of the third fiber is $70 \% \mathrm{Al}_{2} \mathrm{O}_{3}, 28 \% \mathrm{SiO}_{2}^{2}, 2 \% \mathrm{~B}_{2} \mathrm{O}_{3}$ and its structure is completely mullite (ref. 10). It is designated in this paper as ABS $\left(2 \% \mathrm{~B}_{2} \mathrm{O}_{3}\right.$, 
100\% Mullite). All fibers were heat cleaned at $500^{\circ} \mathrm{C}$ for $3 \mathrm{hr}$ to remove any organic sizing material prior to testing.

\section{Thermal Diffusivity Tests of Multilayer Insulations}

The thermal diffusivity of the multilayer insulations was determined using the apparatus described previously in reference 11 . In this test, the samples to be tested are instrumented and inserted in a sample holder shown in figure 4. This holder has been designed to minimize edge effects of the insulations during heating. The instrumented insulations are placed in the apparatus and the pressure is reduced to $20 \mathrm{~mm} \mathrm{Hg}$. Quartz lamps are used with a 2-min programmed schedule to achieve and maintain a temperature of approximately $1000^{\circ} \mathrm{C}$ on the top surface of the sample holder shown in figure 4 . The backface temperature of the insulation sample is measured for a period of approximately $13 \mathrm{~min}$. The maximum backface temperature is reached within the first 6-7 min, and from this the rate of change in temperature $\left(T_{H}-T_{C}\right) / \Delta t$ is determined. All samples were tested with the folls on the cold side.

Figures 5-8 show the temperature response of the multilayer insulations and the AFRSI. The test results are the average of approximately $6-8$ test samples from each configuration, and the actual test data are summarized in table 4. It can be seen that multilayer Configurations 1, 2, and 4 had lower heat transfer rates than Configuration 5 (AFRSI). However, Configuration 3 had significantly higher rates. The fibers in Insulation 3 have a diameter of $5 \mu \mathrm{m}$ compared to the 1.5-3-um-diameter fibers in the other insulations. The higher compaction and larger fibers could contribute to the higher backface temperature $r$ ise of this configuration.

\section{Computer Model of Multilayer Insulations}

The data shown in figure 5 were analyzed using a specially developed, one-dimensional heat transfer model. The model simulates the test arrangement shown in figure 4. Twenty-eight thermal elements are used: 10 elements for the insulation, one for each of the stainless steel-scrim cloth pairs, five for the ERCI base, and one each for the two fabric liners and the coating. The model includes radiation from the heat lamps while they are on and radiation from the chamber walls after the 120 sec heating cycle. Thermal radiation within the samples is accounted for as well as the temperature dependence of thermal conductivity.

The analysis proceeds in several steps. First, the time dependent heat load at the top surface and the heat loss at the bottom surface are determined by systematically varying them until the calculated back surface temperatures match the measured temperatures for the baseline model. Then the effective thermal conductivity of a stainless steel and a scrim cloth configuration is determined by systematically varying the conductivity until the backface temperatures match those measured for the configuration with the baseline temperature environment imposed. Finally, thermal properties of the test configuration components are varied to determine their sensitivity to the temperature. 
Some preliminary results of this analysis are shown in figure 9 for Configuration 1. Because of the time consuming nature of the temperature matching process for the baseline model only an approximate match was achieved for this preliminary phase, but because the same heating environment is imposed on both the baseline and the test configurations, the trends and relative changes should be valid indications for the more precise models. The solid curves in the figure are the calculated simulations to the test data. Although the calculated levels are somewhat higher at $420 \mathrm{sec}$, the difference between these curves is about the same as the temperature difference in the data at that time. Because the baseline samples were slightly thicker than the Configuration 1 samples, a correction was made to account for this difference. The backface temperature for a baseline sample with the same thickness as Configuration 1 is shown by the dashed curve.

Several factors contribute to the difference between these curves. The results of the analysis of these differences are shown in figure 10. This figure is in effect a snapshot of figure 9 taken at $420 \mathrm{sec}$. The temperature difference at that time is bracketed by the solid lines. The internal dashed lines show the contribution of the various blanket components to that difference. One contributor is the thermal mass of the stainless steel foils. If the foils were reduced from $0.005 \mathrm{~cm}$ to $0.0005 \mathrm{~cm}$ thick, the backface temperature would be reduced from the baseline temperature to the level of the top dashed line. The density and conductivity of the Q-felt in Configuration 1 are lower than those of the baseline material. If the Q-felt thermal properties are used in the baseline model the temperature is reduced further. The difference between the lower dashed line and the Configuration 1 level is attributable to the performance of the multilayer insulation (MLI). The effective MLI conductivity that would correlate with this difference is about that of $a^{i} r$. No effect of conduction through the sewing thread is apparent. The berefit gained by the MLI is fairly small, but measurable for this test environment. However, MLI is intended for use in space vacuum where gas conductivity between foils is negligible and the effective conductivity can be very small. If the MLI conductivity were one third that of air, the backface temperature would be reduced to the level of the lowest dashed line in figure 10. Conductivities much lower than this are easily achieved with MLI blankets. The thermal conductivity of the baseline material will also be much lower in vacuum. The tradeoff of these factors and their weight implications will be the subject of future development work.

\section{Tension Tests of Fibers}

The silica and ABS fibers were tested at high temperatures to determine the tensile strength, strain and moduli. The properties of some of the single fibers have been reported previously in references 10 and 12 . However, it was desired to determine the properties using uniform heating and testing conditions for all the fibers to compare them accurately. All testing was performed using an MTS 810 test machine. Instron single fiber grips were used to grip the test specimens. A heating furnace previously used for yarns and fabrics (ref. 13) was modified to eliminate convective currents from the 
furnace disturbing the single fibers and softening of the adhesive bonding of the fibers to the end tabs. Fiber areas were calculated using individual fiber cross-sectional dimensions as measured in an optical microscope. Some fibers were round while others were oval or oblong in cross-sectional shape. Scanning electron microscope photographs were also taken to verify fiber shape and average areas of the fibers. These areas and shapes corresponded well with literature values from the manufacturers. The testing was performed using a procedure described previously in reference 14 .

Figures 11-13 show the tensile strengths, tensile moduli, and tensile strains of the silica and three ABS fibers. The test temperatures shown were adjusted to test each fiber near its maximum use temperature. The long length of the fiber $(20 \mathrm{~cm})$ and heated zone $(5 \mathrm{~cm})$ were used in order to be able to correct the tensile modulus calculations. As shown in figure 8 the tensile strength of the $\mathrm{SiO}_{2}$ and $\mathrm{ABS}\left(141 \mathrm{~B}_{2} \mathrm{O}_{3}\right)$ fiber were approximately the same. The third $A B S$ fiber--ABS $\left(2 \% \mathrm{~B}_{2} \mathrm{O}_{3}\right.$, $100 \%$ mullite)--showed the highest tensile strengths at all temperatures tested retaining its strength up to $1000^{\circ} \mathrm{C}$.

Figure 12 indicates the tensile modulus of the fibers. In general, the ABS fibers had much higher values than the silica fibers with the ABS ( $2 \%$ $\mathrm{B}_{2} \mathrm{O}_{3}, 100 \%$ mullite) fiber showing the highest modulus with only a slight reduction at $1000^{\circ} \mathrm{C}$.

Figure 13 indicates the strain of the fibers. The rapid increase in the tensile strain of the ABS $\left(14 \% \mathrm{~B}_{2} \mathrm{O}_{3}\right)$ fiber at $700^{\circ} \mathrm{C}$ is attributed to its high boria content and morphology (ref. 15). The ABS (14\% $\mathrm{B}_{2} \mathrm{O}_{3}, 70 \%$ crystalline) fiber which is similar in composition did not increase similarly due to its high crystallinity. Again, the ABS $\left(2 \% \mathrm{~B}_{2} \mathrm{O}_{3}, 100 \%\right.$ mullite) does not lose any of its properties up to approximately $1000^{\circ} \mathrm{C}$. These values obtained correspond well with those reported previously in references 10 and 12 .

\section{CONCLUSIONS}

A study has been made of the performance of multilayer insulation systems for use in the $1000^{\circ} \mathrm{C}$ temperature range. A number of insulation types have been evaluated in combination with a stainless steel reflective shield and an ABS scrim cloth spacer material. In addition, the fllaments used in the construction of these configurations have been evaluated. The principal results obtained are as follows:

1. The apparent thermal diffusivity of multilayer configurations utilizing small diameter fibers in the insulation was lower than the baseline AFRSI insulation.

2. The optical properties of commercially available stainless steel foil seem to be adequate up to $800^{\circ} \mathrm{C}$ for use as a radiation shield in multilayer assemblies.

3. A simplified heat transfer model permits engineering calculations of multilayer insulation thermal response based upon spacer, shield, and insulation thermophysical properties and physical characteristics of the system.

4. A good correlation was obtained between the experimental test data and the one-dimensional heat transfer model developed for multilayer insulations. 
5. The aluminoborosilicate $\left(2 \% \mathrm{~B}_{2} \mathrm{O}_{3}\right.$, $100 \%$ mullite) filaments had the highest mechanical properties at elevated temperatures.

\section{REFERENCES}

1. Goldstein, H.; Leiser, D.; Larson, H.; and Sawko, P. M.: "Improved Thermal Protection System for the Space Shuttle Orbiters," AIAA paper 82-0630, May 1982.

2. Sawko, P. M.: "Effect of Processing Treatments on Strength of Silica Thread for Quilted Ceramic Insulation on Space Shuttle," SAMPE Quarterly, Vol. 16, No. 4, July 1985, pp. 17-21.

3. Mui, D.; and Clancey, H. M.: "Development of a Protection Ceramic Coating for Shuttle Orbiter Advanced Flexible Reusable Surface Insulation (AFRSI)," Ceramic Eng. and Sci. Proc., Vol. 6, No. 7-8, July-Aug. 1985, pp. $793-805$.

4. Sawko, P. M.: "Tailorable Advanced Blanket Insulations (TABI)," Proceedings of the Joint NASA/Clemson University Conference on Advanced Engineering Fibers and Textile Structures for Composites, Greenville, S.C., Nov. 1987.

5. Riede, P. M.; and Wang, K. I. J.: "Characteristics and Applications of Some Super Insulations," Advances in Cryogenic Engineering, Vol. 5, Plenum Press, 1959, p. 209.

6. Heathman, J. H.: "Hydrogen Tankage Applications to Manned Aerospace Systems," AFFDL TR-68-75, April 1968.

7. NASA-MFSC FY 86 AFE Definition Review Report, May 30, 1986.

8. Viskantan, R.: "Heat Transfer by Conduction and Radiation in Absorbing and Scattering Materials," J. Heat Transfer (ASME), 1965.

9. Sawkc, P. M.: "Effect of Processing Treatments on Strength of Silica Thread I'or Quilted Ceramic Insulation on Space Shuttle," SAMPE Quarterly, Vol. 16, No. 4, July 1985, pp. 17-21.

10. Johnson, D. D.; Holtz, A. R.; and Grether, M. F.: "Properties of Nextel 480 Ceramic Fibers," Proceedings of the 11th Annual Conference and Advanced Ceramic Materials, Cocoa Beach, Florida, Jan. 18-23, 1987.

11. Smith, M.: "Thermal Diffusivity Apparatus," NASA Tech Brief 10642, Ames Research Center, Jan. 1979.

12. Holtz, A. R.; and Grether, M. F.: "High Temperature Properties of Three Nextel Ceramic Fibers," Proceedings of the 32nd International SAMPE Conference, Anaheim, CA, April 1987.

13. Smith, M.; Estrella, C.; and Katvala, V.: "High Temperature Tensile Furnace for Flexible Ceramics," NASA Tech Brief 11589, Ames Research Center, Vol. 10, No. 6, November-December 1986.

14. ASTM D3379-73, "Test Method for Tensile Strength and Young's Modulus for High Modulus Single Filament Materials," American Society for Testing and Materials, Philadelphia, PA.

15. Sawko, P. M.; and Tran, H. K.: "Influence of the Thread Construction on Strength of Ceramic Sewing Threads," SAMPE Quarterly, Vol. 18, No. 4, July 1987. 
TABLE I. - MATERIALS SELECTED FOR MULTILAYER CONFIGURATIONS

\begin{tabular}{|l|c|l|}
\hline \multicolumn{1}{|c|}{ MATERIAL } & USE/FUNCTION & \multicolumn{1}{|c|}{ REASON FOR SELECTION } \\
\hline $\begin{array}{l}\text { ALUMINOBOROSILICATE } \\
\text { FABRIC }\end{array}$ & OUTER FABRIC & $\begin{array}{l}\text { THERMAL STABILITY, LOW } \\
\text { THERMAL CONDUCTIVITY }\end{array}$ \\
\hline $\begin{array}{l}\text { SILICA, ALUMINOBOROSILICATE, } \\
\text { ALUMINA }\end{array}$ & INSULATION & $\begin{array}{l}\text { LOW THERMAL CONDUCTIVITY, } \\
\text { SPECIFIC HEAT, SCATTERING AND } \\
\text { ABSORPTION COEFFICIENTS }\end{array}$ \\
\hline STAINLESS STEEL FOIL & SHIELD & $\begin{array}{l}\text { RELATIVELY HIGH REFLECTANCE } \\
\text { AT HIGH TEMPERATURES }\end{array}$ \\
\hline $\begin{array}{l}\text { ALUMINOBOROSILICATE SCRIM } \\
\text { CLOTH }\end{array}$ & SPACER & $\begin{array}{l}\text { STABILITY, LOW THERMAL } \\
\text { CONOUCTIVITY, LOW WEIGHT }\end{array}$ \\
\hline
\end{tabular}

TABLE II.- DESCRIPTION OF CONFIGURATIONS

\begin{tabular}{|c|c|c|}
\hline $\begin{array}{l}\text { COMPONENT/ } \\
\text { PROPERTY }\end{array}$ & CONFIGURATION 1.4 & $\begin{array}{l}\text { CONFIGURATION } 5 \\
\text { (BASELINE) }\end{array}$ \\
\hline TOP SURFACE & $\begin{array}{l}\text { ALUMINOBOROSILICATE } \\
\left(62 \% \mathrm{Al}_{2} \mathrm{O}_{3}, 14 \% \mathrm{~B}_{2} \mathrm{O}_{3}\right. \\
\left.24 \% \mathrm{SHO}_{2}\right) \text { FABAIC }(1), 5 \text { HARNES8 } \\
\text { SATIN WEAVE, } 600110 \text { DENIER, } \\
19 \times 18 \text { YARNS } / \mathrm{cm}, 244 \mathrm{~g} / \mathrm{m}^{2}\end{array}$ & $\begin{array}{l}\text { SILICA } 199.9 \% \mathrm{SIO}_{2} \text { FABRIC(5), } \\
5 \text { HARNESS SATIN WEAVE, } 300 \\
2 / 8 \text { DENIER, } 15 \times 9 \text { YARNS } / \mathrm{cm} \text {, } \\
681{\mathrm{~g} / \mathrm{m}^{2}}^{2}\end{array}$ \\
\hline INSULATION & 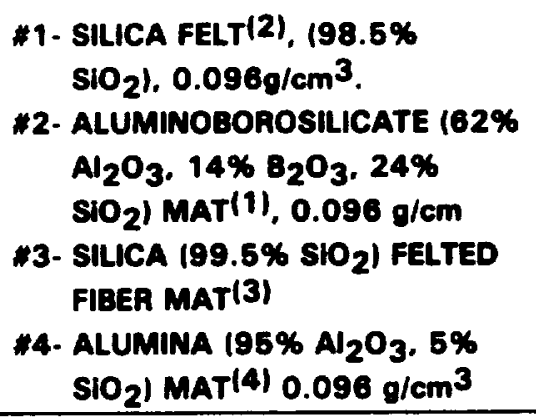 & $\begin{array}{l}\text { SILICA } 198.6 \% \mathrm{SIO}_{2} \text { FELT(2), } \\
0.096 \mathrm{~g} / \mathrm{cm}^{3}\end{array}$ \\
\hline SPACER & $\begin{array}{l}\text { ALUMINOBOROSILICATE }(62 \% \\
\left.\mathrm{Al}_{2} \mathrm{O}_{3} 14 \% \mathrm{~B}_{2} \mathrm{O}_{3}, 24 \% \mathrm{SIO}_{2}\right) \\
\text { SCRIM(1) } 6001 / 0 \text { DENIER, } 5 \times 5 \\
\text { YARNS } / \mathrm{cm}, 67.8 \mathrm{~g} / \mathrm{m}^{2}\end{array}$ & NONE \\
\hline SHIELD & STAINLESS STEEL FOIL $.005 \mathrm{~cm}$ & NONE \\
\hline BOTTOM SUAFACE & SAME AS TOP SURFACE & SILICA $\left(95 \% \mathrm{SiO}_{2}\right)$ FABRIC (5) \\
\hline THREAD & $\begin{array}{l}\text { ALUMINOBOROSILICATE } \\
\left(62 \% \mathrm{~A}_{2} \mathrm{O}_{3}, 14 \% \mathrm{~B}_{2} \mathrm{O}_{3}\right. \\
\left.24 \% \mathrm{SH}_{2}\right), 6001 / 4 \text { DENIER }\end{array}$ & $\begin{array}{l}\text { SILICA }\left(99.9 \% \mathrm{SiO}_{2}\right)^{(5)} \\
3002 / 8 \text { DENIER }\end{array}$ \\
\hline THICKNESS, cm & $\begin{array}{ll}* 1-0.833 & * 3-0.640 \\
* 2-0.805 & \# 4-0.838\end{array}$ & 0.914 \\
\hline
\end{tabular}

(1) 3M COMPANY, ST. PAUL, MN

(2) MANVILLE CORP., DENVER, CO

(3) LYDALL INC., ROCHESTER. NH

(4) BABCOCK AND WILCOX, ATLANTA, GA

(5) J.P. STEVENS CO., GREENVILLE, NC 
TABLE III.- TYPICAL THERMAL PROPERTIES OF INSULATIONS IN MULTILAYER CONE IGURATIONS

\begin{tabular}{|c|c|c|c|c|c|}
\hline $\begin{array}{l}\text { CONFIGU. } \\
\text { RATION }\end{array}$ & INSULATION & $\begin{array}{l}\text { NOMINAL } \\
\text { DENSITY } \\
\left(\mathrm{g} / \mathrm{cm}^{3}\right)\end{array}$ & $\begin{array}{c}\text { FIBER } \\
\text { DIAMETER } \\
\left.\text { I } m \text { m } \times 10^{-3}\right)\end{array}$ & $\begin{array}{c}\text { SPECIFIC } \\
\text { HEAT } \\
1000^{\circ} \mathrm{C} \\
\left.\text { (W-soc/0 } / 0^{\circ} \mathrm{C}\right)\end{array}$ & $\begin{array}{c}\text { THERMAL } \\
\text { CONDUCTIVITY } \\
\text { ( } 1000^{\circ} \mathrm{C} \\
\left(W^{\prime} / \mathrm{m}^{3} \mathrm{C} \times 10^{-2}\right)\end{array}$ \\
\hline 1 & $\begin{array}{l}\text { SILICA FELT (1) } \\
\left(98.5 \% \mathrm{SiO}_{2}\right)\end{array}$ & 0.096 & 1.5 & 0.349 & 1.58 \\
\hline 2 & $\begin{array}{l}\text { ALUMINOBOROSILICATE } \\
\text { MAT(2) }\left(62 \% \mathrm{Al}_{2} \mathrm{O}_{3} \text {. }\right. \\
\left.24 \% \mathrm{SIO}_{2}, 14 \% \mathrm{~B}_{2} \mathrm{O}_{3}\right)\end{array}$ & 0.096 & 3.5 & 0.388 & 2.16 \\
\hline 3 & $\begin{array}{l}\text { SILICA FELTED FIBER } \\
\operatorname{MAT}^{(3)}\left(99.0 \% \mathrm{SIO}_{2}\right) \\
\end{array}$ & 0.136 & 5.0 & 0.258 & 1.87 \\
\hline 4 & $\begin{array}{l}\text { ALUMINA MAT(4) } \\
\left(95 \% \mathrm{Al}_{2} \mathrm{O}_{3} 5 \% \mathrm{SiO}_{2}\right)\end{array}$ & 0.096 & 3.0 & 0.336 & 1.80 \\
\hline 5 & $\begin{array}{l}\text { SILICA FELT } \\
\left(98.6 \% \mathrm{SIO}_{2}\right)\end{array}$ & 0.096 & 1.6 & 0.349 & 1.58 \\
\hline
\end{tabular}

(1) MANVILLE CORP. DENVER, CO

(2) 3M COMPANY, ST. PAUL. MN

(3) LYDALL INC., ROCHESTER, NH

(4) BABCOCK AND WILCOX, ATLANTA, GA

- at 1 atMosphere

TABLE IV.- SUMMARY OF THERMAL RESPONSE DATA

\begin{tabular}{|c|c|c|c|c|}
\hline CONFIGURATION & $\begin{array}{c}\text { TEMP. RISE } \\
\left({ }^{\circ} \mathrm{C} / \mathrm{soC}\right)\end{array}$ & $\begin{array}{c}\text { MAX. BACKFACE } \\
\text { TEMP. }{ }^{\circ} \mathrm{C}\end{array}$ & $\begin{array}{c}\text { TIME TO REACH MAX. } \\
\text { TEMP. (sac) }\end{array}$ & $\begin{array}{c}\text { BACKFACE TEMP. } \\
\text { ( } 5 \text { min }{ }^{\circ} \mathrm{C}\end{array}$ \\
\hline 1 & $1.46 \pm 0.18$ & $278 \pm 15$ & $460 \pm 25$ & $264 \pm 23$ \\
\hline 2 & $1.62 \pm 0.13$ & $300 \pm 29$ & $426 \pm 28$ & $298 \pm 26$ \\
\hline 3 & $1.97 \pm 0.18$ & $331 \pm 4$ & $375 \pm 12$ & $341 \pm 18$ \\
\hline 4 & $1.40 \pm 0.09$ & $284 \pm 4$ & $456 \pm 9$ & $284 \pm 16$ \\
\hline 5 (BASELINE) & $2.09 \pm 0.13$ & $321 \pm 17$ & $349 \pm 13$ & $328 \pm 18$ \\
\hline
\end{tabular}




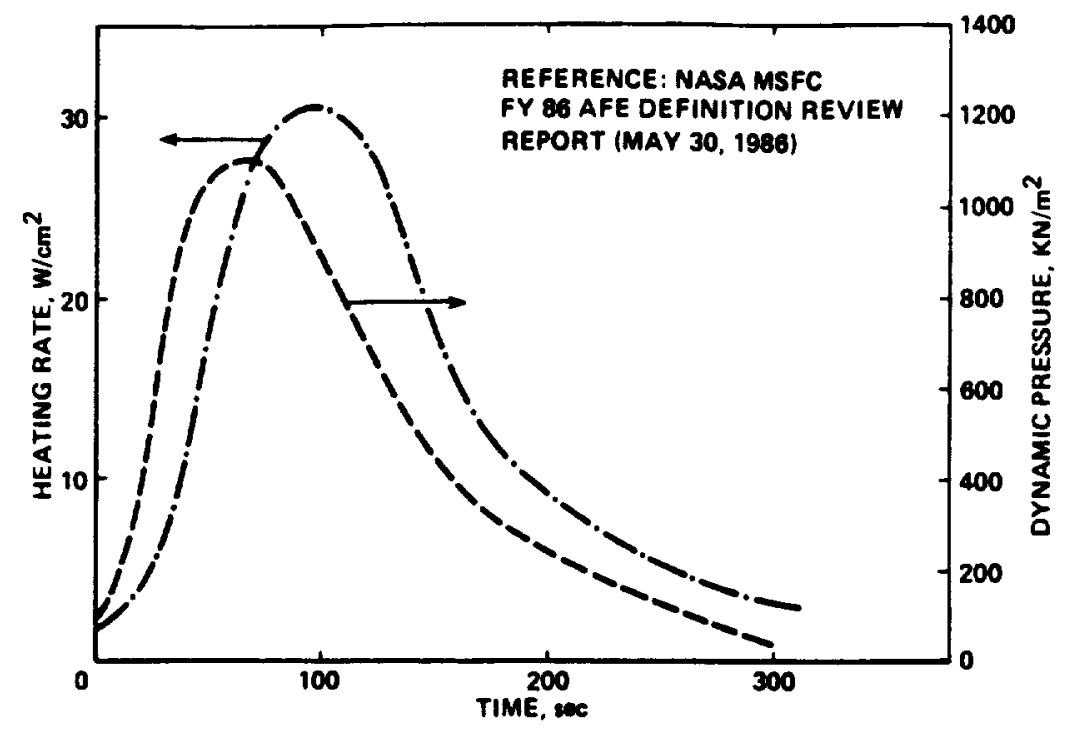

Figure 1.- AFE Heating Rate and Dynamic Pressure During Atmospheric Pass.

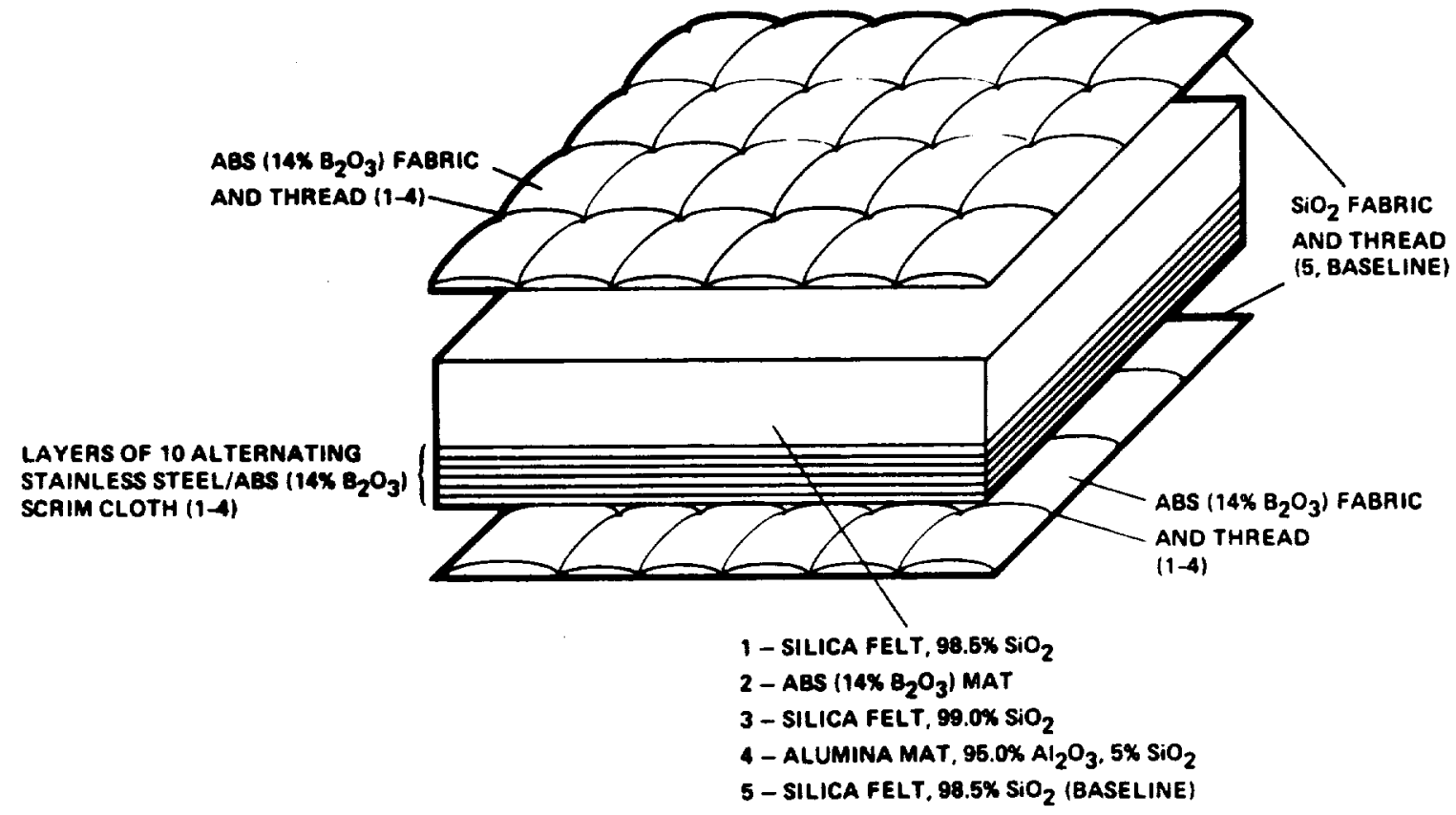

Figure 2.- Multilayer Configurations. 


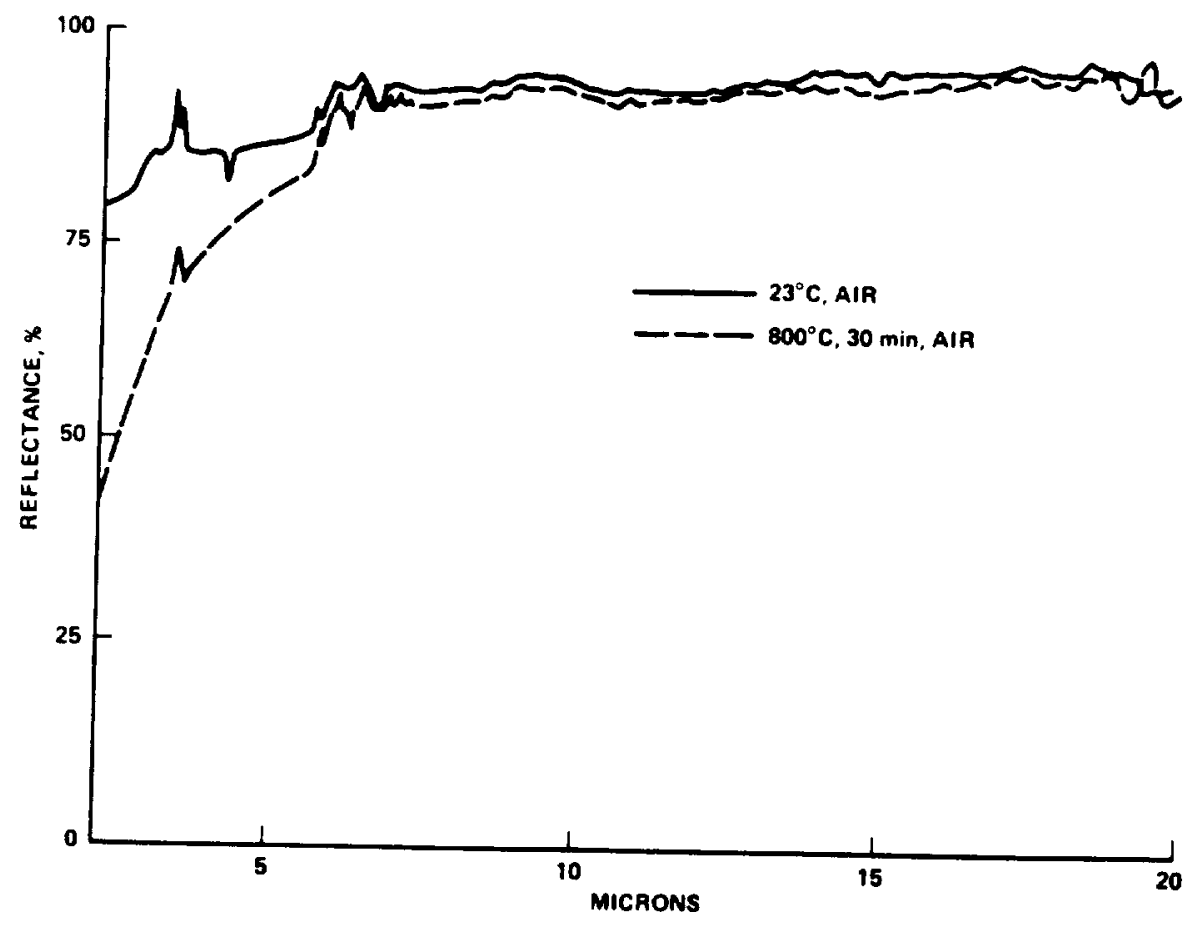

Figure 3.- Reflectance of Stainless Steel Foils.

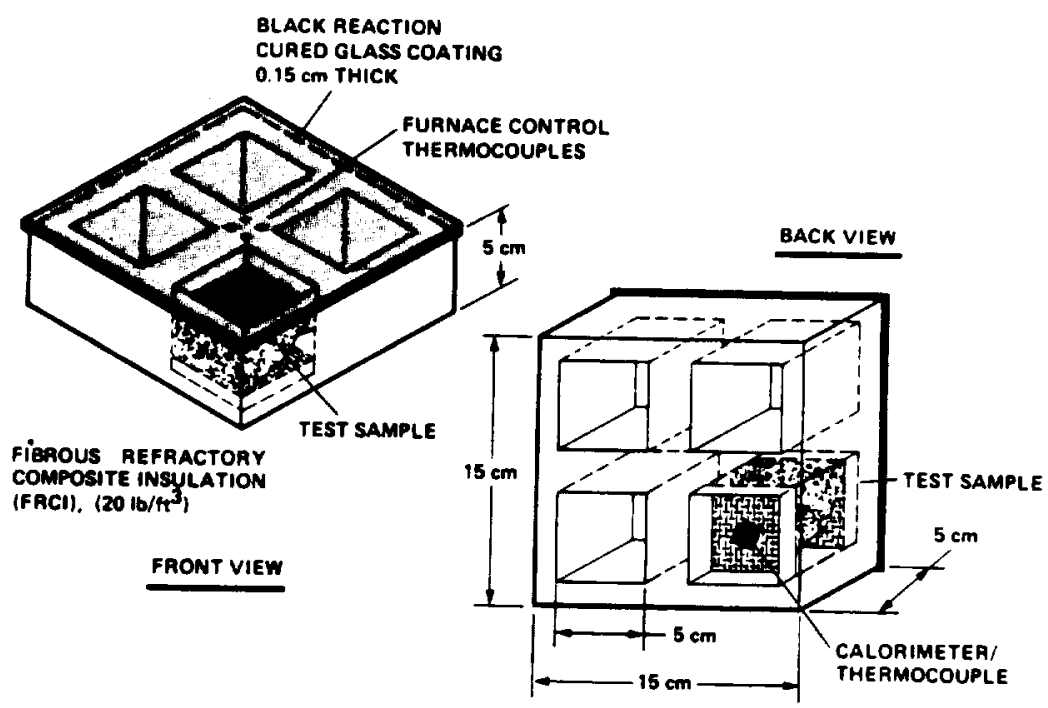

Figure 4.- Thermal Diffusivity Sample Holder. 


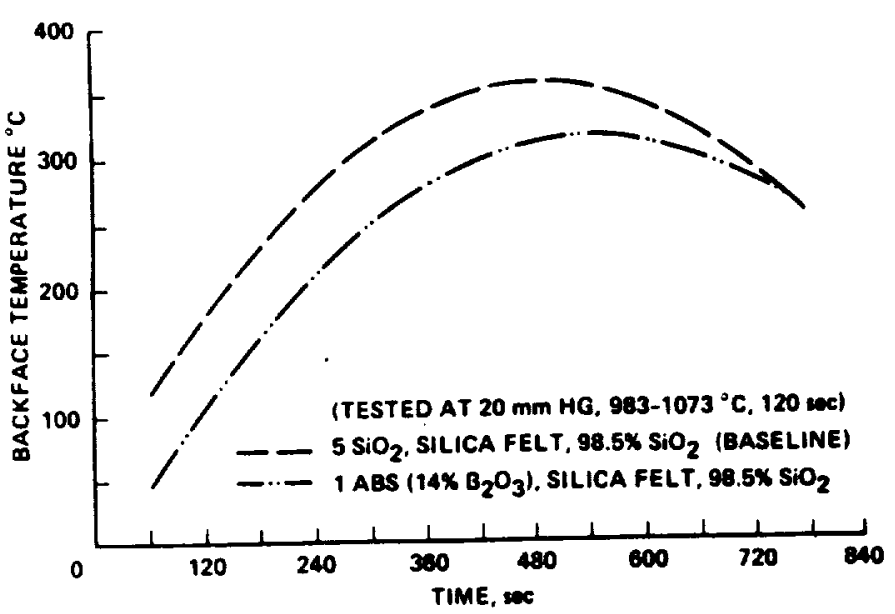

Figure 5.- Thermal Response of Multilayer Configuration 1.

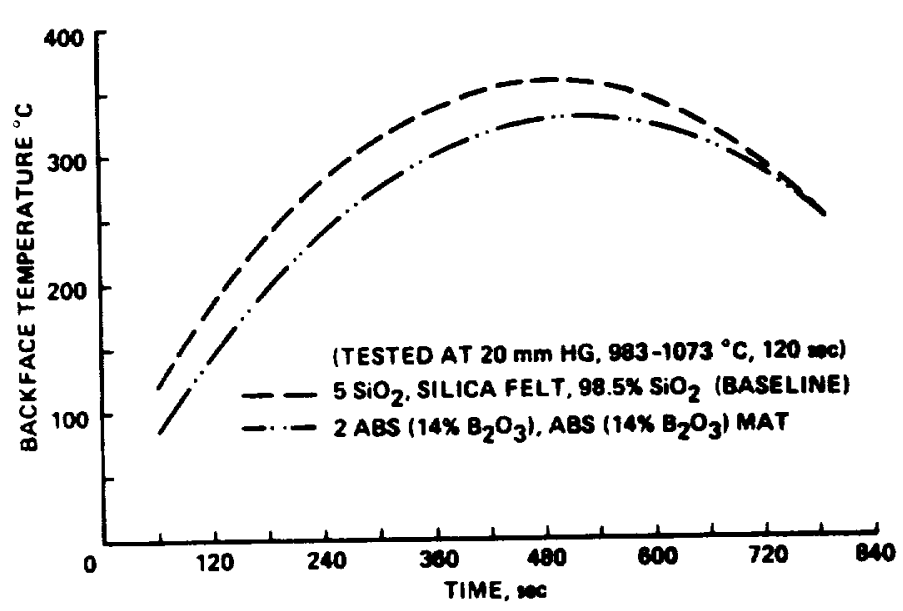

Figure 6.- Thermal Response of Multilayer Configuration 2.

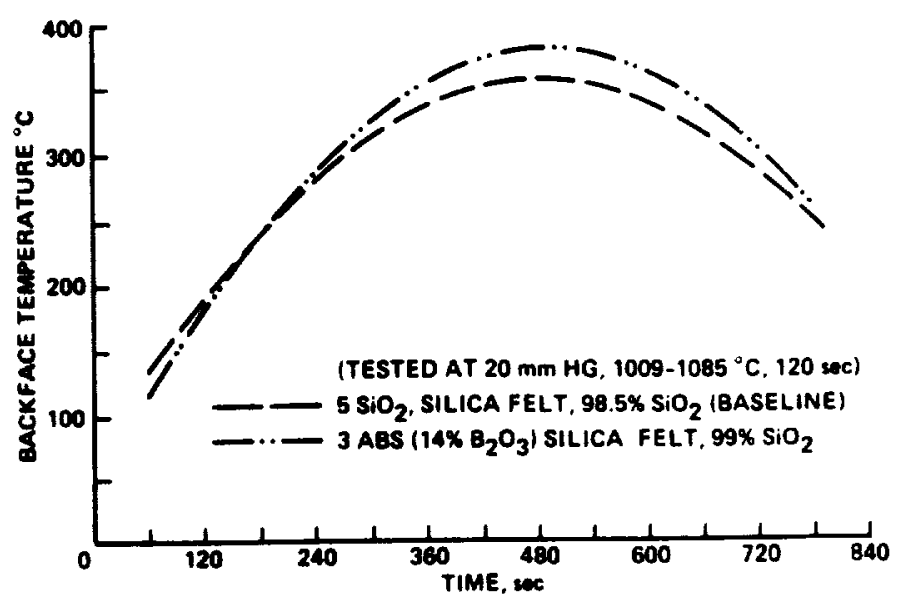

Eigure 7.- Thermal Response of Multilayer Configuration 3.

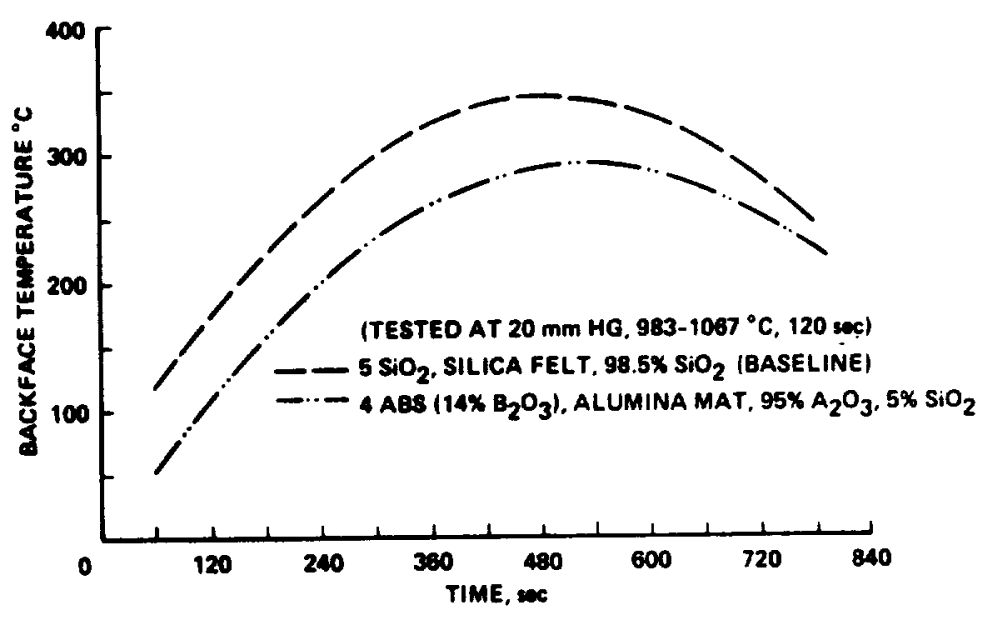

Figure 8.- Thermal Response of Multilayer Configuration 4.

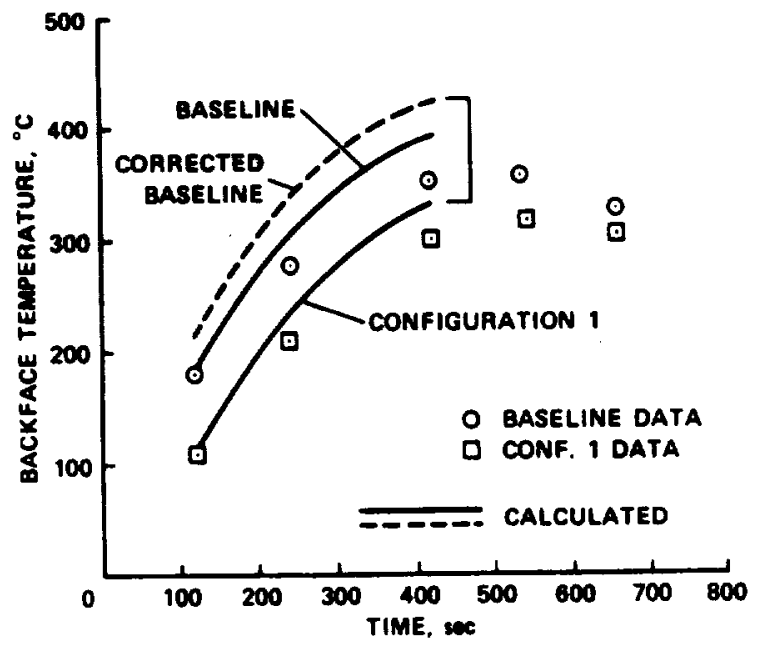

Figure 9.- Backface Temperatures Calculated for Data Analysis. 


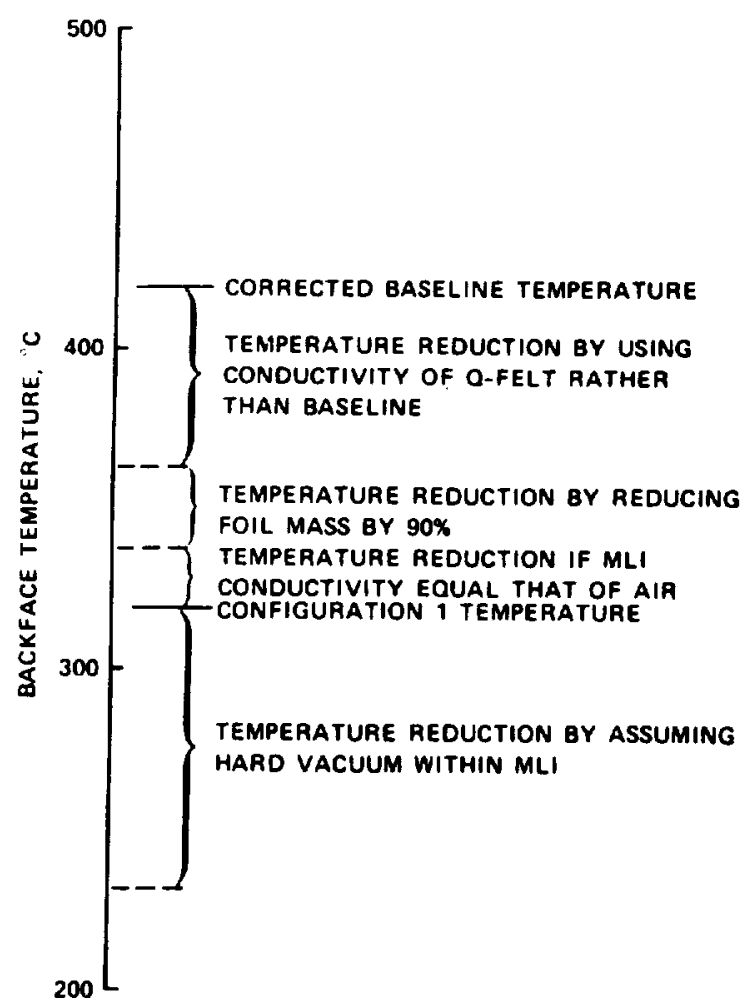

Eigure 10.- Results of Analysis of Difference Between Baseline and Configuration 1 Temperature Data at $420 \mathrm{Sec}$.

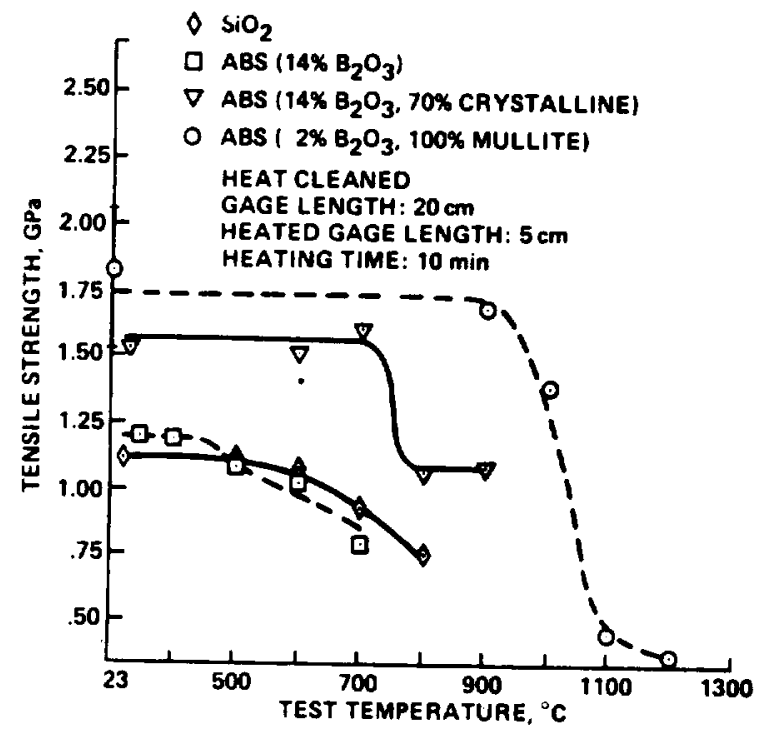

Figure 11.- Tensile Strength of Silica and Aluminoborosilicate Single Filaments.

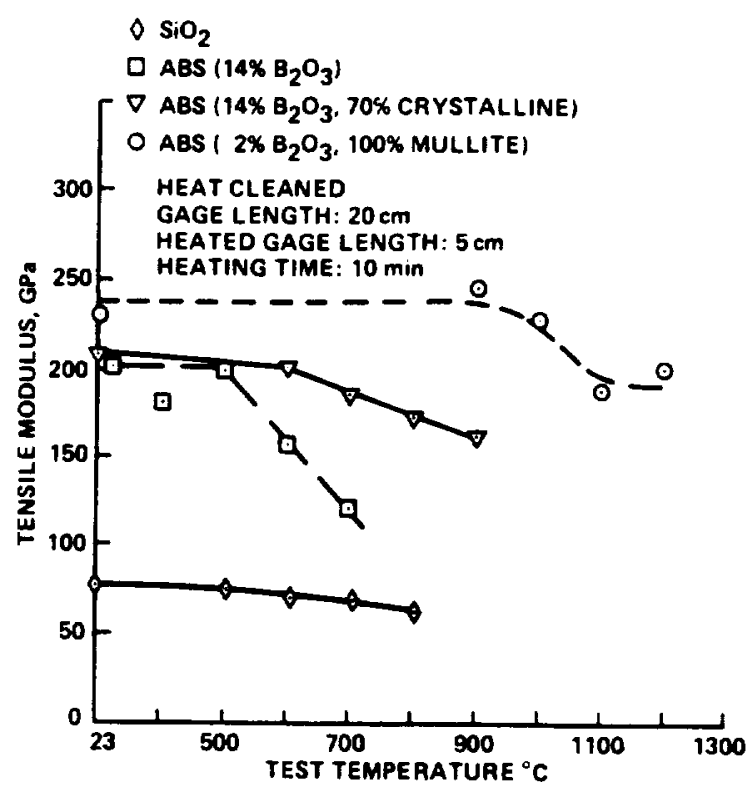

Figure 12. Tensile Modulus of Silica and Aluminoborosilicate Single Filaments.

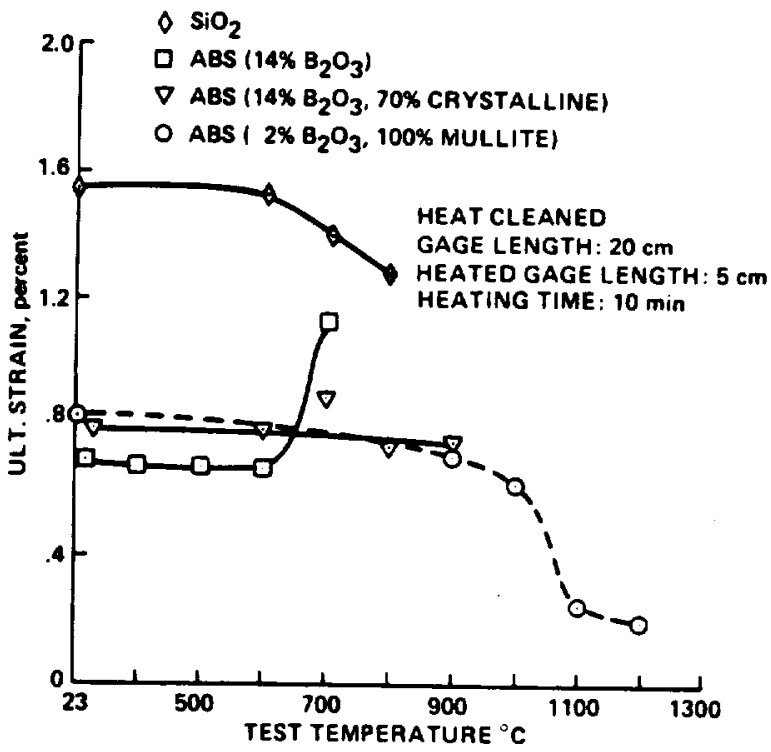

Figure 13. Tensile Strain of Silica and Aluminoborosilicate Single Filaments. 


\begin{tabular}{|l|l}
\hline $\begin{array}{l}\text { 1. Report No. } \\
\text { NASA TM-100059 }\end{array}$ & 2. Government Accession No. \\
\hline
\end{tabular}

4. Title and Subtitle

High-Temperature Properties of Ceramic Fibers and Insulations for Thermal Protection of Atmospheric Entry and Hypersonic Cruise Vehicles
3. Recipient's Catalog No.

5. Report Date

February 1988

6. Performing Organization Code

7. Author(s) Demetrius A. Kourtides, William C. Pitts (Eloret Institute, Palo Alto, CA), Myrian Araujo (San Jose State Univ., San Jose, CA), and R. S. Zimmerman (Univ. of Wyoming, Laramie, WY)

9. Performing Organization Name and Address

Ames Research Center

Moffett Field, CA 94035

\section{Sponsoring Agency Name and Address}

National Aeronautics and Space Administration Washington, DC 20546

8. Performing Organization Report No.

A-88059

10. Work Unit No.

$506-43-31$

11. Contract or Grant No.

13. Type of Report and Period Covered

Technical Memorandum

14. Sponsoring Agency Code

15. Supplementary Notes

Point of Contact: Demetrius A. Kourtides, Ames Research Center, MS 234-1, Moffett Field, CA, (415) $694-4784$ or FTS $464-4784$

16. Abstract

Multilayer insulations which will operate in the $500^{\circ} \mathrm{C}$ to $1000^{\circ} \mathrm{C}$ temperature range are being considered for possible applications on aerospace vehicles subject to convective and radiative heating during atmospheric entry. The insulations described in this paper consist of ceramic fabrics, insulations, and metal foils quilted together using ceramic thread. As these types of insulations have highly anisotropic properties, the total heat transfer characteristics of these insulations must be determined. Data are presented on the thermal diffusivity and thermal conductivity of four types of multilayer insulations and are compared to the baseline Advanced Flexible Reusable Surface Insulation (AFRSI) currently used on the Space Shuttle Orbiter. In addition, the high-temperature properties of the fibers used in these multilayer insulations are discussed. The fibers investigated included silica and three types of aluminoborosilicate (ABS). Static tension tests were performed at temperatures up to $1200^{\circ} \mathrm{C}$ and the ultimate strain, tensile strength, and tensile modulus of single fibers were determined.

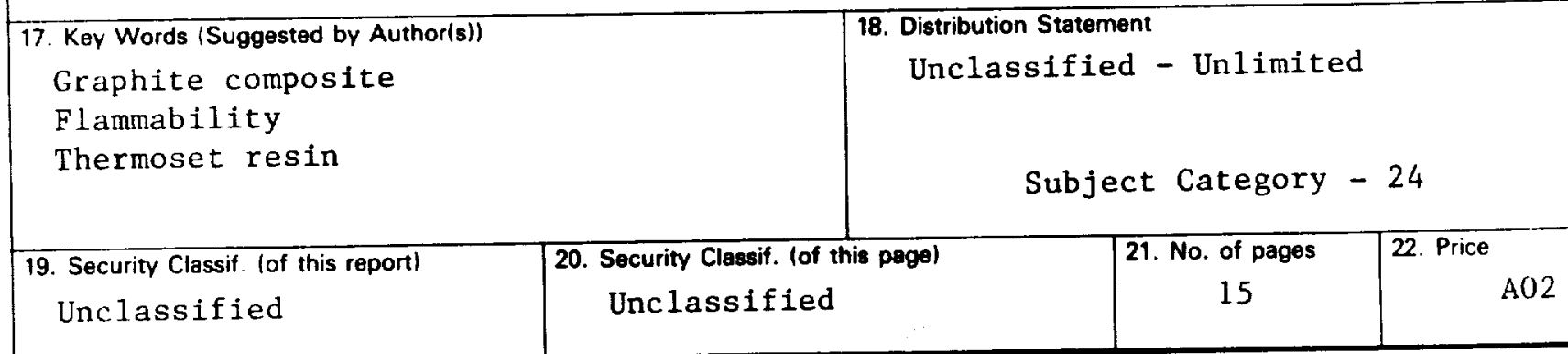

